\title{
Author Correction: Stem cells define adipose depot differences
}

\section{Shimona Starling}

Correction to: Nature Reviews Endocrinology https://doi.org/10.1038/s41574-022-00637-y, published online 25 January 2022.

In this Research Highlight, the original version of the figure supplied by Jae Bum Kim, Seoul National University (Histological images of visceral epididymal adipose tissue (EAT) and subcutaneous inguinal adipose tissue (IAT) from control, cold-exposed and obese mice) included duplicate control images for EAT and IAT due to a file labelling error. The control panels of EAT and IAT have been updated to the correct images. The obesity panels of EAT and IAT were also updated to use the same cohort set.

https://doi.org/10.1038/s41574-022-00644-z I Published online 7 February 2022

(c) Springer Nature Limited 2022 